\title{
İkinci Ürün Koşullarında Ekim Sıklığının Pamuğun (Gossypium hirsutum L.) Verim, Verim Unsurları ve Lif Özellikleri Üzerine Etkisi
}

\author{
Filiz Güneş SADIK', Mustafa Ali KAYNAK ${ }^{* 2}$ \\ 'Gıda Tarım ve Hayvancılık Bakanlığı, İlçe Müdürlüğü, Söke/Aydın. \\ ${ }^{2}$ Adnan Menderes Üniversitesi, Ziraat Fakültesi, Tarla Bitkileri Bölümü, Aydın.
}

Özet: Bu çalışma, buğday hasadından sonra ikinci ürün olarak yetiştirilen pamukta, ekim sıklığının verim, verim unsurları ve lif özelliklerine etkisini belirlemek amacıyla, Aydın ilinde 2015 üretim yılında yapılmıştır. Çalışmada, Flash pamuk çeşidi bitki materyali olarak kullanılmıştır. Deneme, tesadüf blokları deneme desenine göre üç tekerrürlü olarak yürütülmüştür. Çalışmada, sekiz farklı sıra üzeri ekim sıklığı $(3,6,9,12,15,18,21$ ve $24 \mathrm{~cm})$ oluşturulmuştur.

Çalışmada, kütlü pamuk verimi, ilk koza açma gün sayısı, bitki boyu, odun dalı sayısı, meyve dalı sayısı, koza sayısı, I. pozisyon koza sayısı, 2. pozisyon koza sayısı, koza kütlü pamuk ağırlı̆ı, çırçır randımanı, lif uzunluğu, lif inceliği, lif kopma dayanıklıı̆̆ ve lif olgunluğu özellikleri incelenmiştir.

Çalışma sonucunda; ekim sıklığının kütlü pamuk verimi, ilk koza açma gün sayısı, odun dalı sayısı, meyve dalı sayısı, koza sayısı, I. pozisyon koza sayısı ve koza kütlü pamuk ağırlı̆̆ özelliklerine önemli, diğer özelliklere ise önemsiz etkisinin olduğu saptanmıştır. Araştırmada, bitki sıklı̆ı azaldıkça kütlü pamuk verimi, odun dalı sayısı, koza sayısı ve I. pozisyon koza sayısının önemli oranda arttığı, ilk koza açma gün sayısı ve meyve dalı sayısının ise önemli oranda azaldığı belirlenmiştir. Kütlü pamuk verimi yönünden değerlendirildiğinde, ikinci ürün pamuk üretiminde en uygun sıra üzeri mesafenin 18 ile $24 \mathrm{~cm}$ arasında olması gerektiği sonucuna varılmıştır.

Anahtar Kelimeler: pamuk, ekim sıklığ, verim, lif özellikleri

\section{The Effects of Plant Density on Yield and Yield Components and Fiber Properties in Cotton (Gossypium hirsutum L.) Under the Wheat/Cotton Double Crop Production Conditions}

Abstract: This study was conducted in 2015 production year in Aydin Province in order to determine the effect of planting density to yield, yield factors and fiber characteristics in cotton grown as secondary product after wheat crops. In the study, Flash cotton type was used as material. The experiment was performed in compliance with randomize complete block design with three replications. In the study, planting density was created on eight different rows (3, $6,9,12,15,18,21$ and $24 \mathrm{~cm})$.

In the study, seed cotton yield, number of days to open the first boll, plant height, number of monopodial branches, number of sympodial branches, number of bolls, I st position boll number, 2nd position boll number, seed cotton weight per boll, ginning percentage, liber length, liber fineness, fiber strength and fiber maturity characteristics were examined.

In the study, it was detected that planting density had significant impact on seed cotton yield, number of days to open the first boll, number of monopodial branches, number of sympodial branches, number of bolls, I st position boll number and seed cotton weight per boll characteristics, and insignificant impact on other characteristics. In the research, it was determined that when planting density was decreased, seed cotton yield, number of monopodial branches, number of bolls and Ist position boll number is increased significantly; number of days to open the first boll and number of sympodial branches is decreased significantly. When evaluated in terms of seed cotton yield, it is concluded that the most suitable distance on row for secondary product cotton production should be between 18 and 24 centimeters.

Keywords: cotton, planting density, yield, fiber characteristics

\section{GíRiş}

Ülkemiz için stratejik bir ürün olan pamuk Ege Bölgesinin de karakteristik ürünlerinden biri olmasına karşın son yıllarda ana ürün ekim alanları Ege Bölgesinde ve Aydın ilinde giderek azalmaktadır. İkinci ürün tarımı ise Aydın'da günden güne yaygınlaşmaktadır. İkinci ürün pamuk tarımında yüksek verim ve kaliteli ürün için başta ekim sıklığı olmak üzere agronomik çalışmaların yenilenmesinde yarar bulunmaktadır.

Pamuk tarımında verim, birim alanda bulunan bitki sayısı, bitki başına koza sayısı ve bir kozanın kütlü ağırlığı ile yakından ilgilidir. Teorik olarak bitki sayısı artınca birim alandan daha fazla sayıda tarak, çiçek ve koza elde edileceği görüşünden yola çıkan bazı araştırııılar, çeşide de bağlı olarak sık ekimin verim, bitkisel ve teknolojik özelliklere olumlu etkisinin olduğunu ve böylece üretim girdilerinin de azaltılabileceğini belirtmişlerdir (Kaynak ve ark., 1994).

Pamuk üretimi doğal koşullarda yapıldığından, kütlü pamuk verimi; çeşidin genetik yapısına ve üretim sezonu süresince uygulanan sulama, gübreleme, ziraii mücadele, hasat gibi kültürel işlemler ile iklim ve toprak koşullarına göre farklılık gösterebilmektedir (Kıllı, 2005).

Türkiye'de buğday hasadından hemen sonra ekimi yapılan ikinci ürün pamuk yetiştiriciliğine ilişkin araştırmalarda, ana ürün pamuk üretimine göre ikinci ürün pamuk üretiminde yetişme süresi daha kısa çeşitlerin kullanılabileceği (Gencer ve ark., 2003), ana ürün pamuk üretimine göre ikinci ürün pamuk üretiminde kütlü pamuk verimin azaldığı ve lif teknolojik özelliklerinin de olumsuz yönde etkilendiği belirtilmektedir (Kıllı, 2005; Kıllı ve Bölek, 2005).

Bu çalışma, Aydın ekolojik koşullarında, hububat hasadından sonra ikinci ürün olarak yetiştirilen pamukta, ekim sıklığının verimi, verim unsurlarını ve lif özelliklerini nasıl etkileyeceğini

*Sorumlu Yazar: mkaynak@adu.edu.tr

Bu çalışma, yüksek lisans tezi ürünü olup, ADÜBAP tarafindan desteklenmiştir.

Geliş Tarihi: 6 Şubat 2017

Kabul Tarihi: 12 Nisan 2017 
İkinci Ürün Koşullarında Ekim Sıklığıın Pamuğun (Gossypium hirsutum L.) Verim, Verim Unsurları ve Lif Özellikleri Üzerine Etkisi

ortaya koymak ve bu konuda yapılacak çalışmalara kaynak oluşturmak amacıyla yürütülmüştür.

\section{MATERYAL ve YÖNTEM}

\section{Materyal}

Çalışmada, Gosyypium hirsutum L. türüne ilişkin erkenci olgunlaşma grubuna ait Flash pamuk çeşidi materyal olarak kullanılmıştır.

\section{Deneme Yerinin İklim ve Toprak Özellikleri}

Denemenin yapıldığı Aydın ili Söke İlçesinde, 2015 yılı HaziranKasım ayları arasını içeren bitki gelişim periyodu süresince ortalama sıcaklık değerlerinin $28.4^{\circ} \mathrm{C}$ (Ağustos) ile $16.4^{\circ} \mathrm{C}$ (Kasım) arasında değişim gösterdiği, yetişme süresince toplam 526.7 mm yağış düştüğü, olgunlaşma ve hasat dönemi olan Ekim-Kasım aylarında yağış miktarının oldukça yüksek düzeyde (4I2 mm) olduğu (Anonim, 20I5), yapılan toprak analizinde ise deneme arazisinin ise killi bünyeye sahip, organik madde miktarının düşük, hafif alkali ve tuzsuz olduğu tespit edilmiştir.

\section{Yöntem}

Deneme, tesadüf blokları deneme desenine göre üç tekerrürlü olarak yürütülmüştür. Ekim, ön bitki olan buğday hasadından sonra 15 Haziran 2015 tarihinde, sıra arası $70 \mathrm{~cm}$, sıra üzeri $3 \mathrm{~cm}$, sıra uzunluğu $12 \mathrm{~m}$ olan, 6 sıralı parsellere hassas ekim makinasıyla yapılmıştır. Çıkıştan sonra sıra üzerindeki bitkiler arasında 3, 6, 9, 12, 15, 18, 21 ve $24 \mathrm{~cm}$ boşluk bırakılacak şekilde seyreltme yapılarak sekiz farklı bitki sıklığı oluşturulmuştur. Bir dekarda bulunan bitki sayısı oluşturulan sıra üzeri bitki sıklığına göre sırasıyla 476|9, 23809, I5873, I 1904, 9524, 7937, 6803 ve 5952 adet arasında değişmiştir. Çalışmada, diğer kültürel işlemler bölgede yapılmakta olan üretim koşullarına göre yapılmıştır.

Denemede, hasat 23 Kasım 2015 tarihinde elle bir kez, her parsel için 14 m ${ }^{2}$ lik alanda yapılmıştır.

Çalışmada, kütlü pamuk verimi, ilk koza açma gün sayısı, bitki boyu, odun dalı sayısı, meyve dalı sayısı, koza sayısı, I. pozisyon koza sayısı, 2. pozisyon koza sayısı, koza kütlü pamuk ağırlığı, çırçır randımanı, lif uzunluğu, lif inceliği, lif mukavemeti ve lif olgunluğu özellikleri incelenmiştir (Baran, 20I3).

\section{BULGULAR ve TARTIŞMA}

Buğday sonrası ikinci ürün olarak ekilen pamukta farklı ekim sıklığı uygulamasında elde edilen, incelenen özelliklere ilişkin varyans analizi kareler ortalaması sonuçları Çizelge I'de, incelenen özelliklere ait ortalama değerler ve oluşan gruplar ise Çizelge 2'de verilmiştir.

Çizelge I'de, ekim sıklıkları arasında; kütlü pamuk verimi, ilk koza açma gün sayısı, odun dalı sayısı, meyve dalı sayısı, koza sayısı, ।. pozisyon koza sayısı ve koza kütlü pamuk ağırlığı özellikleri yönünden önemli, bitki boyu, 2. pozisyon koza sayısı, çırçır randımanı, lif uzunluğu, lif inceliği, lif mukavemeti ve lif olgunluğu özellikleri yönünden ise önemsiz oranda farklılık olduğu görülmektedir.

\section{Kütlü Pamuk Verimi(kg/da)}

Çizelge 2'de, en yüksek verimin $375.6 \mathrm{~kg} / \mathrm{da}$ ile $21 \mathrm{~cm}$ sıra üzeri ekim sıklığında, bunu azalan sırayla, sıra üzeri $18 \mathrm{~cm}$ (364.3 kg/da), $24 \mathrm{~cm}(344.3 \mathrm{~kg} / \mathrm{da}), 6 \mathrm{~cm}(303.0 \mathrm{~kg} / \mathrm{da}), 15$ $\mathrm{cm}(298.6 \mathrm{~kg} / \mathrm{da}), 12 \mathrm{~cm}(294.0 \mathrm{~kg} / \mathrm{da})$ ve $3 \mathrm{~cm}(292.0 \mathrm{~kg} /$ da) ekim sıklıkları izlemektedir. Ekim sıklı̆ının verime etkisi değerlendirildiğinde $21 \mathrm{~cm}, 18 \mathrm{~cm}$ ve $24 \mathrm{~cm}$ arasında önemli bir farklııı olmadığı ancak bu ekim sıklıklarında diğer ekim sıklıklarına göre verimin önemli oranda daha yüksek olduğu görülmektedir. En düşük verim, 3 cm $(292.0$ kg/da) sıra üzeri ekim sıklığında elde edilmiştir. Genel olarak birim alandaki bitki sayısı arttıkça kütlü pamuk veriminin de azaldığı görülmektedir. Bu sonuç, ikinci ürün pamuk tarımında ekim sıklıgının ana ürün pamuk tarımındaki ekim sıklığına $(70 \times 20 \mathrm{~cm})$ benzer olduğunu ortaya koymaktadır.

Araştırmadan elde edilen verim değerleri; Akhtar ve ark. (2002)'nın en yüksek kütlü pamuk veriminin en geniş bitki aralığında oluştuğunu belirten çalışması ve Wanjura (1980) bitki aralığı yeknesaklığı arttıkça verimin artış gösterdiğini belirten çalışmasıyla da uyumludur. Gencer ve ark. (2003) Çukurova Bölgesinde yapılan çalışmada, buğday sonrası pamuk yetiştiriciliğinde ikinci ürüne uygun çeşitlere ilişkin kütlü pamuk veriminin 216 kg ile 444 kg arasında değiştiğini; Karademir ve ark. (2006) ikinci ürün olarak on farklı pamuk hat/çeşidinin materyal olarak kullanıldığı çalışmada verim potansiyelinin 2004 yllında 383.13 kg/da, 2005 yllında ise 445.08 kg/da'a kadar ulaştığııı; Söyler ve Temel (2007) buğday sonrası ikinci ürün pamuk olarak en yüksek verimin 2002 yılında 290.2 kg/ da, 2003 yılında 195 kg/da arasında olduğunu; Evliyaoğlu ve Kızıl (1998) buğday sonrası ikinci ürün pamuk tarımında en yüksek verimin $207 \mathrm{~kg} / \mathrm{da}$ olduğunu belirten çalışmalarla da benzerlik göstermektedir. Kaynak ve ark. (1994), Kaynak

Çizelge I. İncelenen özelliklere ilişkin varyans analizi kareler ortalaması

\begin{tabular}{|c|c|c|c|c|c|c|c|}
\hline $\begin{array}{l}\text { Varyasyon } \\
\text { Kaynagı }\end{array}$ & $\underset{\substack{\text { Kütlü Pamuk } \\
\text { Verimi }}}{\text {. }}$ & $\begin{array}{l}\text { İlk Koza Açma } \\
\text { Gün Sayısı }\end{array}$ & Bitki Boyu & Odun Dalı Sayısı & $\begin{array}{l}\text { Meyve Dalı } \\
\text { Sayısı }\end{array}$ & Koza Sayısı & $\begin{array}{c}\text { I.pozisyon Koza } \\
\text { sayIsI }\end{array}$ \\
\hline Tekerrür & $1.410 .792 *$ & 0.875 & 53.247 & 0.022 & 0.190 & 0.286 & 0.108 \\
\hline Ekim Sıklığı & $3.581 .619^{* *}$ & $1.85 I^{* *}$ & 17.292 & $0.172^{* *}$ & $0.346^{* *}$ & $2.182^{* *}$ & $0.961 *$ \\
\hline Hata & 374.030 & 0.351 & 23.744 & 0.015 & 0.069 & 0.289 & 0.454 \\
\hline Genel & 1.440 .406 & 0.853 & 24.346 & 0.063 & 0.163 & 0.865 & 0.578 \\
\hline $\begin{array}{l}\text { Varyasyon } \\
\text { Kaynagı }\end{array}$ & $\begin{array}{c}\text { 2.pozisyon Koza } \\
\text { sayısı }\end{array}$ & $\begin{array}{c}\text { Koza Kütlü } \\
\text { Pamuk Ağırlığı }\end{array}$ & $\begin{array}{c}\text { Çırçır } \\
\text { Randımanı }\end{array}$ & Lif Uzunluğu & Lif İnceliği & $\begin{array}{c}\text { Lif Kopma } \\
\text { Dayanıklılığı }\end{array}$ & Lif Olgunluğu \\
\hline Tekerrür & 0.530 & 0.028 & 0.496 & 0.791 & 1.297 & 0.249 & 0 \\
\hline Ekim Sıklı̆̆ı & 0.108 & $0.028 * *$ & 0.134 & 0.253 & 1.021 & 0.510 & 0 \\
\hline Hata & 0.159 & 0.007 & 0.253 & 0.524 & 1.069 & 0.694 & 0 \\
\hline Genel & 0.175 & 0.015 & 0.238 & 0.465 & 1.074 & 0.599 & 0 \\
\hline
\end{tabular}

*\%5 seviyesinde önemli, **\% I seviyesinde önemli. 
Çizelge 2. Incelenen özelliklere ait ortalama değerler ve oluşan gruplar

\begin{tabular}{|c|c|c|c|c|c|c|c|}
\hline $\begin{array}{l}\text { Sıra Üzeri Ekim } \\
\text { Sıklığı } \\
(\mathbf{c m})\end{array}$ & $\begin{array}{l}\text { Kütlü Pamuk } \\
\text { Verimi } \\
\text { (kg/da) }\end{array}$ & $\begin{array}{l}\text { İlk Koza Açma } \\
\text { Gün Sayısı } \\
\text { (gün) }\end{array}$ & $\begin{array}{l}\text { Bitki Boyu } \\
\text { (cm) }\end{array}$ & $\begin{array}{c}\text { Odun Dalı } \\
\text { Sayısı } \\
\text { (adet/bitki) }\end{array}$ & $\begin{array}{c}\text { Meyve Dalı } \\
\text { Sayısı } \\
\text { (adet/bitki) }\end{array}$ & $\begin{array}{l}\text { Koza Sayısı } \\
\text { (adet/bitki) }\end{array}$ & $\begin{array}{l}\text { I.pozisyon } \\
\text { Koza Sayısı } \\
\text { (adet/bitki) }\end{array}$ \\
\hline $3 \mathrm{~cm}$ & $292.0 \mathrm{~b} *$ & $125.00 \mathrm{a}$ & 109.86 & $0.13 d$ & $9.10 \mathrm{a}$ & $8.40 b$ & $6.46 a b$ \\
\hline $6 \mathrm{~cm}$ & $303.0 \mathrm{~b}$ & $124.33 \mathrm{ab}$ & 111.63 & $0.20 \mathrm{~d}$ & $8.80 \mathrm{ab}$ & $8.30 b$ & $6.30 c$ \\
\hline $9 \mathrm{~cm}$ & $296.6 b$ & $124.00 \mathrm{abc}$ & 114.46 & $0.30 \mathrm{bcd}$ & $8.83 a b$ & $8.30 \mathrm{~b}$ & $6.36 c$ \\
\hline $12 \mathrm{~cm}$ & $294.0 \mathrm{~b}$ & $123.66 \mathrm{bcd}$ & 112.00 & $0.63 a b$ & $8.26 \mathrm{~cd}$ & $9.53 a$ & $7.63 a$ \\
\hline $15 \mathrm{~cm}$ & $298.6 b$ & $123.00 \mathrm{~cd}$ & 116.26 & $0.66 a b$ & $8.73 a b$ & $9.60 \mathrm{a}$ & $7.16 a b$ \\
\hline $18 \mathrm{~cm}$ & $364.3 a$ & $123.33 \mathrm{bcd}$ & 109.56 & $0.73 a$ & $8.86 a b$ & $9.90 \mathrm{a}$ & $7.36 a b$ \\
\hline $21 \mathrm{~cm}$ & $375.6 a$ & $123.00 \mathrm{~cd}$ & 111.73 & $0.50 \mathrm{bc}$ & $8.06 \mathrm{~d}$ & $10.10 \mathrm{a}$ & $7.63 a$ \\
\hline $24 \mathrm{~cm}$ & $344.3 a$ & $122.66 \mathrm{~d}$ & 109.66 & $0.70 \mathrm{ab}$ & $8.56 b c$ & $10.36 a$ & $7.33 a b$ \\
\hline $\operatorname{LSD}(0.05)$ & 33.9 & 1.04 & öd & 0.48 & 0.46 & 0.94 & 1.18 \\
\hline $\begin{array}{l}\text { Sıra Üzeri Ekim } \\
\text { Sıklığı } \\
(\mathrm{cm})\end{array}$ & $\begin{array}{c}\text { 2.pozisyon Koza } \\
\text { Sayısı } \\
\text { (adet/bitki) }\end{array}$ & $\begin{array}{l}\text { Koza Kütlü } \\
\text { Pamuk Ağırlığı } \\
\text { (g) }\end{array}$ & $\begin{array}{c}\text { Çırçır } \\
\text { Randımanı } \\
(\%)\end{array}$ & $\begin{array}{l}\text { Lif Uzunluğu } \\
(\mathbf{m m})\end{array}$ & $\begin{array}{l}\text { Lif İnceliği } \\
\text { (micronaire) }\end{array}$ & $\begin{array}{l}\text { Lif Kopma } \\
\text { Dayanıklılığı } \\
\text { (g/text) }\end{array}$ & $\begin{array}{c}\text { Lif Olgunluğu } \\
(\%)\end{array}$ \\
\hline $3 \mathrm{~cm}$ & 1.83 & $5.08 a b c$ & 37.22 & 31.11 & 4.99 & 32.53 & 0.85 \\
\hline $6 \mathrm{~cm}$ & 1.80 & $5.05 \mathrm{bcd}$ & 37.18 & 30.44 & 5.00 & 32.03 & 0.86 \\
\hline $9 \mathrm{~cm}$ & 1.76 & $5.19 a b$ & 37.06 & 30.95 & 5.05 & 32.10 & 0.86 \\
\hline $12 \mathrm{~cm}$ & 1.53 & $5.2 \mathrm{la}$ & 37.06 & 30.95 & 5.04 & 32.23 & 0.86 \\
\hline $15 \mathrm{~cm}$ & 1.80 & $5.00 \mathrm{~cd}$ & 36.58 & 30.70 & 4.98 & 31.23 & 0.86 \\
\hline $18 \mathrm{~cm}$ & 1.70 & $4.91 \mathrm{~d}$ & 37.23 & 31.09 & 5.05 & 31.90 & 0.86 \\
\hline $21 \mathrm{~cm}$ & 1.90 & $5.06 \mathrm{abcd}$ & 37.03 & 31.26 & 5.11 & 32.26 & 0.86 \\
\hline $24 \mathrm{~cm}$ & 2.20 & 5.09abc & 37.15 & 31.32 & 5.02 & 32.50 & 0.86 \\
\hline $\operatorname{LSD}(0.05)$ & öd & 0.15 & öd & öd & öd & öd & öd \\
\hline
\end{tabular}

*Aynı harfle gösterilen ortalamalar arasında, 0.05 olasılık sınırına göre önemli farklılık yoktur.

öd: önemli değil.

(1995)'in bitki sıklığı arttıkça kütlü pamuk veriminin arttı̆̆ını belirten çalışmalarıyla uyum göstermemektedir.

\section{İlk Koza Açma Gün Sayısı (gün)}

Çizelge 2'de, en geç koza açım tarihi 125 gün ile $3 \mathrm{~cm}$ sıra üzeri ekim sıklığında elde edilirken, bunu azalan sıra ile $6 \mathrm{~cm}$ (I 24.33 gün), ve $9 \mathrm{~cm}$ (I24 gün), $12 \mathrm{~cm}$ (I23.66 gün), 18 cm (I 23.33 gün), I5 cm (I 23.00 gün), 21 cm (I 23.00 gün) ve $24 \mathrm{~cm}$ ( I 22.66 gün) sıra üzeri ekim sıklıkları izlemektedir. En erken koza açım tarihi ise $24 \mathrm{~cm}$ (I 22.66 gün) sıra üzeri ekim sıklığında olduğu gözlenmiştir. Çalışmada, ekim sıklığının ilk koza açma gün sayısı üzerine önemli etkide bulunduğu, sıra üzeri mesafe arttıkça diğer bir deyişle bitki sıklığı azaldıkça kozanın daha erken açtığı saptanmıştır.

Çalışmada elde edilen değerler; Kaynak ve ark. (1994)'nin bitki sıklığı arttıkça erkenciliğin arttığını belirten çalışması ve Helaloğlu (1987)'nin bitki sıklığının erkenciliğe önemli etkisinin olamadığını belirten çalışması ile uyum göstermemektedir.

Araştırmada ilk koza açma tarihine ilişkin olarak elde edilen veriler; Quınsenberry ve Roark (1976) 90-140 gün, Baran (20।3) Flash pamuk çeşidinde I I8.67 ile I24.67 gün olarak elde ettikleri veriler ile tam uyum göstermektedir.

\section{Bitki Boyu (cm)}

Çizelge 2'de, bitki boyunun $109.56 \mathrm{~cm}(18 \mathrm{~cm})$ ile 116.26 $\mathrm{cm}(15 \mathrm{~cm})$ arasında değiştiği, bitki boyu yönünden sıra üzeri ekim sıkıkları arasında önemli oranda farklılık olmadığı görülmektedir.

Araştırmadan elde edilen bitki boyu değerleri; Söyler ve Temel (2007)'nin 102-1 13cm, Güvercin ve Gencer (2005)'in 83. I$107.8 \mathrm{~cm}$, Kılıç (2008)'ın 73.3-121.53 cm, olarak bildirdikleri bitki boyu değerleri ile uyum göstermektedir. Buna karşın elde edilen değerler, Karademir ve ark. (2007)'nin 87.30-98.80 cm olarak bildirdikleri ile Başbağ ve ark. (2008)'nin 77.57$84.73 \mathrm{~cm}$ olarak bildirdikleri bitki boyu değerlerinin üstünde kalmaktadır.

Bulgularda, ikinci ürün ekimde, ekim sıklığının bitki boyuna önemli etkisinin olmadığı gözlenmiş olup; Kaynak ve ark. (1994) ve Kaynak (1995)'in bitki sıklığı arttıkça bitki boyunun azaldığını belirten çalışmasıyla uyum sağlamamaktadır.

\section{Odun Dalı Sayısı (adet/bitki)}

Çizelge 2'de, en yüksek odun dalı sayısının 0.73 adet ile $18 \mathrm{~cm}$ sıra üzeri ekim sıklığında olduğu, bunu azalan sırayla $24 \mathrm{~cm}$ (0.70 adet), $15 \mathrm{~cm}$ (0.66 adet), $12 \mathrm{~cm}$ (0.63 adet), $21 \mathrm{~cm}$ (0.50 adet), $9 \mathrm{~cm}$ (0.30adet) ve $6 \mathrm{~cm}(0.20 \mathrm{adet})$ sıra üzeri ekim sıklıklarının izlediği, en düşük odun dalı sayısının ise 0.13 adet ile $3 \mathrm{~cm}$ sıra üzeri ekim sıklığında olduğu görülmektedir. Çalışmada, odun dalı sayısı yönünden, sıra üzeri ekim sıkııkarı arasında önemli oranda farklılık olduğu, genelde sıra üzeri mesafe arttıkça diğer bir deyişle birim alandaki bitki sayısı azaldıkça odun dalı sayısı da önemli oranda artmaktadır.

Elde edilen bulgular; Kaynak ve ark. (1994) sıra üzeri uzaklığı azaldıkça odun dalı sayısının azaldığını; Kaynak (1995) sıra arası uzaklığı azaldıkça (bitki sıklığı arttıkça) odun dalı sayısının azaldığını; Düven (1992) bitki sıklığının azalması ile odun dalı sayısının arttığını belirten çalışma ile uyumludur. İncekara ve Turan (1977)'nın bitki sıklığının odun dalı sayısında farklılık oluşturmadığını belirten çalışması ile uyum sağlamamıştır.

Araştırma sonucunda elde edilen odun dalı değerleri; Başbağ ve ark. (2008)in 0.33-I.06 adet/bitki olarak bildirdiği odun 
İkinci Ürün Koşullarında Ekim Sıklığıın Pamuğun (Gossypium hirsutum L.) Verim, Verim Unsurları ve Lif Özellikleri Üzerine Etkisi

dalı sayısı değerleri ile uyuşmaktadır. Kılıç (2008)'ın 0.5-2.50 adet/bitki olarak bildirilen değerleri ile kısmen uyumludur. Karademir ve ark. (2007)'in 2.00-3.30 adet/bitki, Söyler ve Temel (2007)'nin I-3 adet/bitki olarak bildirdikleri odun dalı sayıları üzerinde kalmaktadır.

\section{Meyve Dalı Sayısı (adet/bitki)}

Çizelge 2'de, en fazla meyve dalı sayısı, $3 \mathrm{~cm}$ (9.I adet) sıra üzeri ekim sıklığında olduğu belirlenmiştir. Bunu azalan sıra ile $18 \mathrm{~cm}$ ( 8.86 adet), $9 \mathrm{~cm}$ (8.83 adet), $6 \mathrm{~cm}$ (8.80 adet), $15 \mathrm{~cm}$ (8.73 adet), $24 \mathrm{~cm}$ (8.56 adet) ve $12 \mathrm{~cm}$ (8.56 adet) izlemektedir. En düşük meyve dalı sayısı ise $21 \mathrm{~cm}$ (8.06 adet) ekim sıklı̆̆ında olduğu görülmektedir. Çalışmada, meyve dalı sayısı yönünden ekim sıklıkları arasında önemli oranda farklılık olduğu, $18 \mathrm{~cm}$ sıra üzeri ekim sıklığı hariç tutulduğunda genelde sıra üzeri ekim sıklığı azaldıkça diğer bir deyişle bitki sayısı arttıkça meyve dalının da arttığı belirlenmiştir.

Elde edilen bulgular; Kaynak ve ark. (1994) sıra üzeri uzaklığı azaldıkça meyve dalı sayısının azaldığını; Kaynak (1995) sıra arası uzaklığı azaldıkça (bitki sıklığı arttıkça) meyve dalı sayısının azaldığını; Düven (1992) bitki sıklığının azalması ile meyve dalı sayısının arttığını belirten çalışmalar ile uyumludur. İncekara ve Turan (1977)'nın bitki sıklığının meyve dalı sayısında farklılık oluşturmadığını belirten çalışması ile uyum sağlamamıştır. Araştırmadan elde edilen koza sayısı değerleri; Mustafayev ve ark. (2005)'ın I0.I-I4.6 adet/bitki, Kılıç (2008) I0.I014, I3 adet/bitki olarak belirtikleri koza sayısı değerleri ile yakınlık göstermektedir. Söyler ve Temel (2007)'in 13-17 adet/bitki, Güvercin ve Gencer (2005)'in 12.9-13.8 adet/ bitki, Ekinci ve ark. (2008)'nin II.37-13.03 meyve dalı sayıs। olarak bildirdikleri değerlere göre elde edilen değerler düşük seviyededir.

\section{Koza Sayısı (adet/bitki)}

Aynı çizelgeden, en fazla toplam koza sayısının 10.36 adet ile $24 \mathrm{~cm}$ sıra üzeri ekim sıklı̆ı̆nda olduğu görülmektedir. Bunu azalan sırayla $21 \mathrm{~cm}$ ( 10.10 adet), $18 \mathrm{~cm}$ (9.90 adet), $15 \mathrm{~cm}$ (9.60 adet), $12 \mathrm{~cm}$ (9.53 adet) ve $3 \mathrm{~cm}$ ( 8.40 adet) sıra üzeri ekim sıklıkları izlemektedir. En az toplam koza sayısı ise sıra üzeri $6 \mathrm{~cm}$ (8.30 adet) ve $9 \mathrm{~cm}$ (8.30 adet) ekim sıklıklarında olduğu görülmektedir. Çalışmada, toplam koza sayısı yönünden sıra üzeri ekim sıklıkları arasında önemli oranda farklılık olduğu, sıra üzeri mesafe arttıkça diğer bir deyişle birim alandaki bitki sayısı azaldıkça toplam koza sayısının da önemli oranda arttı̆̆ı belirlenmiştir.

Elde edilen bulgular; Boquet (2005) sulu koşullarda pamukta bitki sıklı̆ıında artışın, bitkideki koza sayısını azalttı̆ı̆ını, ancak $\mathrm{m}^{2}$ ye koza sayısını etkilemediğini; Heithold (1995) ekim sıklığının koza sayısını artırma potansiyeline sahip olduğunu, Akhtar ve ark. (2002) en yüksek koza sayısının, $30 \mathrm{~cm}$ bitki aralı̆ıında oluştuğunu, bunu önemsiz farkla $20 \mathrm{~cm}$ bitki aralığının izlediğini, Kaynak ve ark. (1994), Kaynak (1995), Düven (1992), Heithold (1995) bitki sıklığı arttıkça koza sayılarının azaldığını belirten araştırma bulgularıyla uyum içindedir. Araştırmadan elde edilen koza sayısı değerleri; Ekinci ve ark. (2008)'nın 5. I3-10.50 adet/bitki, Kılıç (2008)'ın 6.8025.00 adet/bitki olarak belirledikleri koza sayısı değerleri ile uyum göstermektedir. Mustayev ve ark. (2005)'nin 12.0-16.2 adet bitki, Karademir ve ark. (2007)'nın 13.33-I5.80 adet/ bitki koza sayısı olarak bildirdikleri değerlere göre ise elde edilen bulgular düşük seviyededir.

\section{Pozisyon Koza Sayısı (adet/bitki)}

Çizelge 2'de, I. Pozisyonda koza sayısının en fazla 7.63 adet ile $21 \mathrm{~cm}$ ve $12 \mathrm{~cm}$ sıra üzeri ekim sıklıklarında olduğu görülmektedir. Bunları azalan sıra ile sıra üzeri $18 \mathrm{~cm}(7.36$ adet), $24 \mathrm{~cm}$ (7.33 adet), $15 \mathrm{~cm}$ (7.16 adet), $3 \mathrm{~cm}$ (6.46 adet) ve $9 \mathrm{~cm}$ ( 6.36 adet) ekim sıklıkları izlemiştir. En az I. pozisyon koza sayısının ise $6 \mathrm{~cm}$ (6.30 adet) ekim sıklığında olduğu görülmektedir. Çalışmada, I. pozisyon koza sayısı yönünden, sıra üzeri ekim sıklıkları arasında önemli oranda farklılık olduğu, genel olarak sıra üzeri mesafe arttıkça diğer bir deyişle birim alandaki bitki sayısı azaldıkça I. pozisyon koza sayısının da arttı̆̆ı belirlenmiştir.

\section{Pozisyon ve Üstü Koza Sayısı (adet/bitki)}

Çizelge 2'de, 2. Pozisyon ve üstü koza sayısının I.53 adet (12 $\mathrm{cm}$ ) ile 2.20 adet $(24 \mathrm{~cm})$ arasında değiştiği, 2.pozisyon ve üstü koza sayısına, sıra üzeri ekim sıklıklarının önemli etkisinin olmadığı belirlenmiştir.

\section{Koza Kütlü Pamuk Ağırlığı (g)}

Çizelge 2'de, en yüksek koza kütlü pamuk ağılığının 5.2I g ile $12 \mathrm{~cm}$ sıra üzeri ekim sıklığında olduğu, bunu azalan sıra ile 9 cm (5.19 g), $24 \mathrm{~cm}$ (5.09 g), $3 \mathrm{~cm}$ (5.08 g), $21 \mathrm{~cm}$ (5.06 g), $6 \mathrm{~cm}(5.05 \mathrm{~g})$ ve $15 \mathrm{~cm}(5.00 \mathrm{~g})$ sıra üzeri ekim sıklıklarının izlediği, en düşük koza kütlü pamuk ağırlığının ise $4.91 \mathrm{~g}$ ile 18 cm sıra üzeri ekim sıklığında olduğu görülmektedir. Çalışmada, sıra üzeri ekim sıklıklarının, koza kütlü pamuk ağıllığını önemli oranda etkilediği belirlenmiştir.

Elde edilen bulgular; Boquet (2005) sulu pamukta bitki sıklığında artışın bitkideki koza ağırlığını azalttı̆̆ını, ancak $\mathrm{m}^{2}$ ye koza sayısını etkilemediğini; Akhtar ve ark. (2002) en yüksek koza ağılığının $30 \mathrm{~cm}$ bitki aralı̆ıında oluştuğunu, bunu önemsiz farkla $20 \mathrm{~cm}$ bitki aralı̆̆ının izlediğini; Kaynak ve ark. ( 1994) sıra üzeri uzaklığı azaldıkça koza kütlü pamuk ağırlığının azaldığını; Kaynak (1995) sıra arası uzaklığı azaldıkça (bitki sıklığı arttıkça) koza kütlü pamuk ağılığının azaldığını; Düven (1992) bitki sıklığının azalması ile koza kütlü pamuk ağırlığının arttı̆̆ını belirten çalışmalar ile uyumludur. Incekara ve Turan ( 1977)'nın bitki sıklığının koza kütlü pamuk ağıllığında farklılık oluşturmadığını belirten çalışması ile uyum sağlamamıştır.

Araştırma neticesinde elde edilen koza kütlü pamuk ağırlığı değerleri; Kılıç (2008)'ın 4.30-5.53 g olarak bildirdiği koza kütlü ağırlığı ile uyumlu olup, Güvercin ve Gencer (2005)'in 5. I-5.9 g olarak bildirdikleri koza kütlü pamuk ağırlığı değerlerinden düşüktür.

\section{Çırçır Randımanı (\%)}

Çizelge 2'de, çırçır randımanının \%36.58 (I5 cm) ile \%37.23 $(18 \mathrm{~cm})$ arasında değiştiği, sıra üzeri ekim sıklı̆ııın, çırçır randımanına önemli bir etkisinin olmadığı belirlenmiştir.

Elde edilen bulgular; Bozbek ve Ünay (2005'ın ekim sıklığının çırçır randımanına önemli etkisinin olmadığını belirten çalışması ile uyumlu olup, Kaynak ve ark. (1994)'nın sıra üzeri uzaklığı azaldıkça çırçır randımanın azaldığını belirten çalışması ile uyum sağlamamıştır.

Araştırmadan elde edilen çırçır randımanı değerleri; Karademir ve ark. (2007)'nın \%37.92-40.55, Güvercin ve Gencer 
(2005)'in \%4I.3-43.9 çırçır randımanı değerlerinden düşük kalmaktadır.

\section{Lif Uzunluğu (mm)}

Çizelge 2'de, lif uzunluğunun $30.44 \mathrm{~mm}(6 \mathrm{~cm})$ ile $31.32 \mathrm{~mm}$ $(24 \mathrm{~cm})$ arasında değişim gösterdiği, sıra üzeri ekim sıklığının, lif uzunluğuna önemli bir etkisinin olmadığı belirlenmiştir. Elde edilen bulgular; Hawkins ve Peacock (I97I), Bridge ve ark. (1973), Baker (1976)'ın ekim sıklığı ile lif uzunluğunun etkilenmediğini belirten çalışması ile uyum sağlamakta; Kaynak ve ark. (1994)'nın sıra üzeri uzaklığı azaldıkça lif uzunluğunun azaldığını belirten çalışması ile uyum sağlamamaktadır.

Araştırmada elde edilen lif uzunluğu değerleri; Güvercin ve Gencer (2005)'in 28.8-30.3 mm, Kılıç (2008)'ın 29.52$32.06 \mathrm{~mm}$ olarak bildirdikleri lif uzunluğu değeriyle kısmen uyuşmaktadır. Söyler ve Temel (2007)'nin 25.72-29.80 mm lif uzunluğu değerlerine göre ise kısa kalmaktadır.

\section{Lif İnceliği (micronaire)}

Çizelge 2'de, lif inceliğinin 3.39 micronaire $(15 \mathrm{~cm})$ ile 5.1 I micronaire $(2 \mathrm{l} \mathrm{cm})$ arasında değiştiği, sıra üzeri ekim sıklı̆ının, lif inceliğine önemli bir etkisinin olmadığı belirlenmiştir.

Elde edilen bulgular; Jones ve Wells (1998)'in, lif inceliğinin bitki sıklığı arttıkça azaldığını belirten çalışması ile uyum sağlamamaktadır. Araştırma sonucunda elde edilen lif incelik değerleri; Söyler ve Temel (2007)'in 4.2-5.I micronaire, Özdemir (2007)'in 5.24 micronaire değerleri ile kısmen uyumludur. Güvercin ve Gencer (2005)'in 3.8-4.4 micronaire olarak bildirdikleri değerlere göre ise elde ettiğimiz lif inceliği değerleri yüksektir.

\section{Lif Kopma Dayanıklılığı (g/text)}

Çizelge 2'de, lif kopma dayanıklılığının $31.23 \mathrm{~g} /$ text $(15 \mathrm{~cm})$ ile $32.53 \mathrm{~g} /$ text $(3 \mathrm{~cm})$ arasında değiştiği, sıra üzeri ekim sıklığının, lif kopma dayanıklılı̆ına önemli bir etkisinin olmadığı belirlenmiştir.

Elde edilen bulgular; Hawkins ve Peacock (197I), Bridge ve ark. (1973) ve Baker (1976) lif kopma dayanıklılığının bitki sıklığı ile etkilenmediğini belirten çalışması ile uyum içinde olup; Kaynak ve ark. (1994)'nın sıra üzeri uzaklığı azaldıkça lif kopma dayanıklılığının azaldığını belirten çalışması ile uyum sağlamamaktadır

Araştırmada elde edilen lif kopma dayanıklıık değerleri; Özbek ve ark. (2009)'nın 29.2-32.9 g/text, Karademir ve ark. (2007)'nın 28.7-31.13 g/text ve Kılıç (2008)'ın 32.43-37.20 g/ text olarak bildirdikleri değerler ile benzerlik göstermektedir.

\section{Lif Olgunluğu (\%)}

Çizelge 2'de, lif olgunluğu değerinin sıra üzeri ekim sıklıklarına göre 0.85 ile 0.86 arasında değiştiği, tüm uygulamalarda olgunluğun hemen hemen aynı olduğu görülmektedir. Çalışmada, sıra üzeri ekim sıklığının, lif olgunluğuna önemli bir etkisinin olmadığı belirlenmiştir. Araştırmada elde edilen lif olgunluk değerleri, Özbek ve ark. (2009)'nın 0.86-0.90 olarak bildirdikleri değerler ile uyumludur.

Pamukta ekim sıklığının incelenen özelliklere etkileri, denemenin yapıldığı yöreye ve ana veya ikinci ürün yetişme koşullarına göre değişebilmektedir. Bu bakımdan araştırmalar arasındaki farklılıklar, kullanılan genotipler, çevresel faktörler ve uygulanan kültürel işlemlerin farklılı̆ından kaynaklanmaktadır.

\section{SONUÇ}

Sonuç olarak, $18 \mathrm{~cm}, 21 \mathrm{~cm}$ ve $24 \mathrm{~cm}$ sıra üzeri mesafelerinde diğer sıra üzeri mesafelere göre önemli oranda daha fazla kütlü pamuk verimi alınması ve $18 \mathrm{~cm}, 21 \mathrm{~cm}, 24 \mathrm{~cm}$ sıra üzeri mesafelerinde kütlü pamuk verimi yönünden önemli farklılık olmaması nedeniyle ikinci ürün pamuk tarımında en uygun sıra üzeri ekim sıklığının 18 ile $24 \mathrm{~cm}$ arasında olması gerektiği, bu sıra üzeri ekim sıklığının da ana ürün pamuk tarımındaki sıra üzeri ekim sıklığına (yaklaşık $20 \mathrm{~cm}$ ) benzer olduğu sonucuna varılmıştır.

\section{KAYNAKLAR}

Akhtar M, Cheema MS, Jamıl M, Faroq MR, Aslam, M (2002) Effect of Plant Density on Four Short Statured Cotton Varieties. Asian Journal of Plant Sciences I (6): 644-645.

Anonim (20I5) Meteoroloji Genel Müdürlüğü Verileri, Ankara. Baker SH (1976) Response of Cotton to Row Patterns and Plant Populations. Agronomy Journal 68:85-88.

Baran FO (2013) İkinci Ürün Koşullarında Farklı Ekim Zamanlarının Pamuğun (G. hirsutum L.) Agronomik Ve Teknolojik Özellikleri Üzerine Etkisi. Yüksek Lisans Tezi, Adnan Menderes Üniversitesi, Aydın.

Başbağ S, Ekinci R, Gencer O (2008) Pamukta Bazı Karakterlere Illişkin Heterotik Etkiler ve Korelasyon Analizleri. Ankara Üniversitesi Ziraat Fakültesi Tarım Bilimleri Dergisi I4 (2) |43-| 47.

Boquet DJ (2005) Cotton in Ultra-Narrow Row Spacing: Plant Density and Nitrogen Fertilizer Rates. Agronomy Journal 97 (I): 279-287.

Bozbek T, Ünay A (2005) Ekim Zamanı ve Bitki Sıklığının Pamuk Verimi Üzerine Etkisi. Anadolu I5 (I): 34 - 43.

Brıdge RR, Meredıth WR, Chısm JF ( 1973) Influence of Planting Method and Plant Population on Cotton (G. hirsutum L.). Agronomy Journal 65: I 104- II0.

Düven E (1992) Çukurova Koşullarında Farklı Gelişme Özelliklerine Sahip Üç Pamuk Çeşidinde (G. hirsutum L.) Sırt ve Düz Toprak İşleme Şekilleri ile Farklı Sıra Üzeri Uzaklıkların Verim ve Verim Unsurlarına Etkisi Üzerine Bir Araştırma. Yüksek Lisans Tezi, Çukurova Üniversitesi, Adana.

Ekinci R, Karademir E, Karademir Ç (2008) Diyarbakır Ekolojik Koşullarında Sırta Ekilen Buğday Sonrası Anıza II. Ürün Pamuk (Gossypium hirsutum L.) Tarımı Olanağının Araştırılması. Bitkisel Araştırma Dergisi I:7- I I.

Evliyaoğlu N, Kızıl D (1998) GAP Bölgesinde Harran Ovası Koşullarında Kırmızı Mercimek Arpa ve Buğdaydan Sonra İkinci Ürün Pamuk Yetiştirilmesi. Köy Hizmetleri Genel Müdürlüğü Şanlıurfa Araştırma Enstitüsü Müdürlüğü Yayınları. Şanlıurfa.

Gencer O, Boyacı K, Yüksek O, Atıcı O (2003) Possibilities of Cultivation of Cotton (Gossypium hirsutum L.) After the Wheat Production in Çukurova Region and Results of the Variety Trial. Institute of Natural and Applied Sciences University of Çukurova, Adana, Turkey, I: 400-40I.

Güvercin RŞ, Gencer O (2005) Pamuk Bitkisinde (Gossypium hirsutum. L.) Erkenciliğin Kalıtımı Verim ve Lif Teknolojik Özellikleri ile Olan Illişkilerin Belirlenmesi. H. Ü. Ziraat Fakültesi Dergisi 9(4):33-42.

Hawkins BS, Peacock HA (197I) Response of 'Atlas' Cotton to Variations in Plants per Hill and Within-Row Spacings. Agronomy Journal 63:611-613.

Heitholt JJ (1995) Cotton Flowering and Boll Retention in Different Planting Configurations and Leaf Shapes. Agronomy Journal 87: 994-998. 
Helaloğlu C (1987) Harran Ovasında İkinci Ürün Olarak Yetiştirilebilecek Soya Çeşitleri. T.C. Tarım Orman ve Köyişleri Bakanlığı, Köy Hizmetleri Genel Müd. Köy Hizm. Şanlıurfa Ara. Ens. Müd. Yayınları. Genel Yay. No:27. Rapor Yay.No: I8. Şanlıurfa.

İncekara F, Turan ZM (1977) Ekim Sıklığının Dört Pamuk Çeşidinde Bazı Agronomik Karakterlere ve Değişik Yöntemlere Göre Analiz Edilen Erkencilik Üzerine Etkisi. E.Ü.Z.F. yayınları. No:303, Ege Üniversitesi Matbaası. Bornova-Izmir.

Jones MA, Wells R (1998) Dry Material Allocation and Fruiting Patterns of Cotton Grown at Two Divergent Plant Populations. Crop Sciences 37: 797-802.

Karademir E, Karademir Ç, Ekinci R (2007) Pamukta Erkencilik, Verim ve Lif Teknolojik Özelliklerin Kalıtımı. Y.Y.Ü.Zir.Fak. Tarım Bilimleri Dergisi 17 (2): 67-72.

Karademir, E, Karademir Ç, Ekinci R, Karahan H (2006). Güneydoğu Anadolu Bölgesi Koşullarında İkinci Ürün Tarımına Uygun Pamuk Çeşitlerinin Belirlenmesi. Ç. Ü. Ziraat Fakültesi Dergisi 2 I (4): I I9- 126.

Kaynak MA (1995) Harran Ovası Koşullarında Farkı Sıra Arası Uzaklıklarının, Erkenci Pamuk Çeşitlerinin Verim ve Verim Unsurlarına Etkisi Üzerine Bir Araştırma. Harran Üniversitesi Ziraat Fakültesi Dergisi I(I): I-I9.

Kaynak MA, Oğlakcı M, Çölkesen M (1994) Harran Ovası Koşullarında, Pamukta (Gossypium hirsutum L.), Farklı Sıra Arası ve Sıra Üzeri Uzaklıklarının Verim, Verim Unsurları ve Lif Özelliklerine Etkisi Üzerinde Bir Araştırma. Tarla Bitkileri Kongresi Bildiri Kitabı, 25-29 Nisan 1994, İzmir, Cilt I:.214-2।7.

Kılıç Y (2008) Mardin/Derik Ekolojik Koşullarında İkinci Ürün Olarak Yetiştirilebilecek Pamuk (G. hirsutum L.) Çeşitlerinin Tarımsal ve Teknolojik Özellikleri ve Bunların Arasındaki İlişkilerin Belirlenmesi Üzerine Bir Araştırma. Yüksek Lisans Tezi, Çukurova Üniversitesi, Adana.
Kıllı F (2005) Effect of Early, Normal and Late Planting Dates on Yield Components of Two Cotton Cultivars Under İrigated Conditions of Turkey. Innovative Scientific Information \& Service Network Bioscience Research 2(I): 38-42.

Kıllı F, Bölek Y (2005) Timing of Planting is Crucial for Cotton Yield. Acta Agriculturae Scandinavica Section B-Soil and Plant Science 56: 155-160.

Mustafayev SA, Efe L, Kıllı F (2005) Azerbaycan'da Elde Edilen Bazı Mutant Pamuk (Gossypium hirsutum L.) Çeşitlerinin Şanlıurfa Koşullarında Verim ve Lif Kalite Özelliklerinin Değerlendirilmesi. Akdeniz Üniversitesi Ziraat Fakültesi Dergisi I8(2) 245-250.

Özbek N, Ekşi İ, Erdoğan H (2009) Melezleme Islahı ile Erkenci Pamuk Çeşitlerinin Elde Edilmesi. Türkiye VIII. Tarla Bitkileri Kongresi Bildiri Kitabı, 19-22 Ekim 2009, Hatay, 747-75I.

Özdemir M (2007) Buğday Sonrası İkinci Ürün Pamuk (G. hirsutum L. ) Üretiminde Ekim Sıklığının Verim Ve Lif Teknolojik Özelliklere Etkisi. Yüksek Lisans Tezi, Kahramanmaraş Sütçü Imam Üniversitesi, Kahramanmaraş. Quisenberry JE, Roark B (1976) Influence of Indeterminate Growth Habit on Yield and Irrigation Water-Use Efficiency in Upland Cotton. Crop Sciences 16:762-765.

Söyler D, Temel N (2007) Hatay Yöresinde Buğdaydan Sonra II. Ürün Olarak Yetiştirilmeye Uygun Pamuk (Gossypium hirsutum L.) Çeşitlerinin Belirlenmesi. Türkiye VII. Tarla Bitkileri Kongresi, 25-27 Haziran 2007, Erzurum, 736-739.

Wanjura DF (1980) Cotton Yield Response to Plant Spacing Uniformity. Transactions of the Amer. Soc. Agric. Engineers 23: 60-64. 